East African Medical Journal Vol. 79 No 10 October 2002

RISK FACTORS FOR PLACENTA PRAEVIA IN SOUTHERN NIGERIA

A.O. Eniola, FWACS, FMCOG, MRCOG, Department of Obstetrics and Gynaecology, North Tyneside General Hospital, Northshields, NE29 8NH. England, A.U. Bako, FWACS, FMCOG, Department of Obstetrics and Gynaecology, Leighton Hospital, Crewe, CWI 42J, England and D.O. Selo-Ojeme, FWACS, FMCOG. MRCOG, Department of Obstetrics and Gynaecology, Barts and the Royal London NHS Trust, London, N1 1BB, England

Request for reprints to: Dr. D.O. Selo-Ojeme, 13 Wingrave Crescent, Brentwood, Essex, CM14 5PA, England

\title{
RISK FACTORS FOR PLACENTA PRAEVIA IN SOUTHERN NIGERIA
}

\author{
A.O. ENIOLA, A.U. BAKO and D.O. SELO-OJEME
}

\begin{abstract}
Objective: To determine the risk factors for placenta praevia in Ile-Ife, southern Nigeria. Design: A prospective case control study.

Setting: A tertiary center - Obafemi Awolowo University Teaching Hospital, Ile-Ife, southern Nigeria.

Subjects: One hundred and thirty six patients with confirmed placenta praevia constituted the cases. Controls consisted of one hundred and thirty six patients who delivered at term immediately after each indexed case and did not have placenta praevia. Results: Cases and controls were similar in terms of twin deliveries $(P=0.72)$ and past history of uterine surgery $(P=0.47)$. After adjusting for confounders, factors associated with risk of placenta praevia were history of retained placenta $[O R=6.7(95 \%$ CI 1.2 36.6)], previous caesarean section $[O R=4.7,(95 \%$ CI 1.9-11.4)], previous abortion $[O R=2.9(95 \%$ CI 1.1-5.1)], grand multiparity $[O R=2.1(95 \%$ CI 1.6-7.1)] and age over 35 years [OR=1.4 $(95 \%$ CI $1.2-6.6)]$.

Conclusions: From our study, the risk factors for placenta praevia are a history of retained placenta, previous caesarean section, previous abortion, grand multiparity and maternal age over 35 years.
\end{abstract}

\section{INTRODUCTION}

Obstetric haemorrhage is still the leading cause of maternal morbidity and mortality in most of subSaharan Africa. In Nigeria, maternal mortality is estimated at 15 per 1000 births(1). The principal cause remains obstetric haemorrhage and bleeding from an abnormally sited placenta is a significant contributor.

Studies in the developed world have associated placenta praevia to a number of risk factors such as previous caesarean section, spontaneous and induced abortions, and increasing maternal age(2). Very little information on the risk factors for placenta praevia exists in the developing countries. It is important to ascertain the risk factors for this potentially fatal condition as this can assist in the identification of the patient at risk and thus help focus on optimal care. The purpose of this study was to determine the risk factors for placenta praevia in southern Nigeria.

\section{MATERIALS AND METHODS}

This case-control study was conducted at Obafemi Awolowo University Teaching Hospitals Complex, Ile-lfe in Osun State, Nigeria. The hospital serves Ile-Ife and its environs in south-western Nigeria with a population of over two million people. The cases in the study were 136 women with the diagnosis of placenta praevia confirmed at caesarean section. Controls were women who delivered babies at term
( $>37$ th week gestation weighing 2500 g or more) immediately after each index case and who did not have placenta praevia. Details of maternal age, past obstetric and gynaecological history and current pregnancy information were obtained from both cases and controls.

Data were analysed using the EPI-Info programme (USD incorporated 2075A west part place, GA 3007/87). Chisquare test with Yates correction and fisher's exact probability tests were used to determine statistical association between risk factors in cases and controls. Calculating the odd ratios and their $95 \%$ confidence intervals derived an estimate of the risk associated with each of the statistically significant factors. Unconditional logistic regression using the SPSS PC+ statistical software was carried out to identify independent risk factors while controlling for confounding variables.

\section{RESULTS}

There were significantly more women who were 35 years and older in cases than controls and generally, the median age of cases was 30 years (mean 28.9, range 20-44 years) which was significantly older $(\mathrm{P}=0.001)$ than controls (median 27, mean 26.7, 17-43 years). Also significantly more cases than controls were grandmultiparous ( $36.1 \%$ vs. $14 \% ; \mathrm{P}=0.001$ ), had a history of previous retained placenta $(8.1 \%$ vs $1.5 \%$; $P=0.02)$, and previous history of placenta praevia and caesarean section $(\mathrm{P}=0.01$ and 0.001 respectively) (Table 1). 
Table 1

Characteristics of cases and controls

\begin{tabular}{|c|c|c|c|c|c|}
\hline & \multicolumn{2}{|c|}{ Cases $(n=136)$} & \multicolumn{2}{|c|}{ Controls $(n=136)$} & \multirow[b]{2}{*}{$P$ value } \\
\hline & No & $\%$ & No & $\%$ & \\
\hline \multicolumn{6}{|l|}{ Age(years) } \\
\hline $\begin{array}{l}<20 \\
21-35\end{array}$ & 1 & 0.7 & 10 & 7.3 & 0.002 \\
\hline $\begin{array}{l}21-35 \\
>35\end{array}$ & 113 & 83.1 & 115 & 84.6 & \\
\hline$>35$ & 22 & 16.2 & 11 & 8.1 & \\
\hline \multicolumn{6}{|l|}{$\begin{array}{l}\text { Parity } \\
0\end{array}$} \\
\hline 0 & 21 & 15.4 & 45 & 33.8 & 0.001 \\
\hline $\begin{array}{l}<5 \\
>5\end{array}$ & 66 & 48.5 & 71 & 52.2 & \\
\hline$>5$ & 9 & 36.1 & 19 & 14.0 & \\
\hline \multicolumn{6}{|c|}{ Previous Caesarean Section } \\
\hline $\begin{array}{l}>1 \\
0\end{array}$ & 37 & 27.2 & 9 & 6.6 & 0.001 \\
\hline 0 & 99 & 72.8 & 129 & & \\
\hline \multicolumn{5}{|c|}{ Previous Retained Placenta } & \\
\hline $\begin{array}{l}\text { Yes } \\
\text { No }\end{array}$ & 14 & 8.1 & 4 & 1.5 & 0.02 \\
\hline No & 125 & 91.9 & 134 & 98.5 & \\
\hline \multicolumn{6}{|c|}{ Previous Placenta Praevia } \\
\hline $\begin{array}{l}\text { Yes } \\
\text { No }\end{array}$ & 16 & 11.8 & 4 & 2.9 & 0.01 \\
\hline No & 120 & 88.2 & 132 & 97.1 & \\
\hline Twin Gestation & 5 & 3.7 & 3 & 2.2 & 0.722 (NS) \\
\hline \multicolumn{6}{|c|}{ Previous history of abortion } \\
\hline Yes & 68 & 50.0 & 31 & 22.8 & 0.001 \\
\hline No & 68 & 50.0 & 105 & 77.2 & \\
\hline \multicolumn{6}{|c|}{ Previous induced abortion } \\
\hline Yes & 34 & 25.0 & 7 & 5.2 & 0.001 \\
\hline No & 102 & 75.0 & 129 & 94.8 & \\
\hline \multicolumn{6}{|c|}{ Previous spontaneous abortion } \\
\hline Yes & 38 & 27.9 & 24 & 17.6 & $0.07(\mathrm{NS})$ \\
\hline No & 98 & 72.1 & 112 & 82.4 & \\
\hline \multicolumn{6}{|c|}{$\begin{array}{l}\text { Previous uterine surgery } \\
\text { Yes }\end{array}$} \\
\hline $\begin{array}{l}\text { Yes } \\
\text { No }\end{array}$ & $\begin{array}{c}2 \\
134\end{array}$ & $\begin{array}{c}1.5 \\
98.5\end{array}$ & $\overline{136}$ & 100 & $0.47(\mathrm{NSS})$ \\
\hline
\end{tabular}

NS $=$ Not Significant

Table 2

Crude and adjusted odds ratios (OR) of risk factors for placenta praevia

\begin{tabular}{lcc}
\hline Factor & Crude $\mathrm{OR}(95 \% \mathrm{Cl})$ & Adjusted OR(95\% Cl) \\
\hline Previous retained placenta & $3.8(1.1-14.0)$ & $6.7(1.2-36.6)$ \\
Previous Caesarean section & $5.3(2.3-12.5)$ & $4.7(1.9-11.4)$ \\
Previous abortion & $3.3(2.0-5.9)$ & $2.9(1.1-5.1)$ \\
Placenta abnormality & $3.81(1-14.2)$ & $2.5(0.7-11.6)$ \\
Parity $>5$ & $3.5(1.8-6.6)$ & $2.1(1.6-7.1)$ \\
Previous placenta praevia & $4.4(1.3-16.1)$ & $1.3(0.3-5.4)$ \\
Age $>35$ years & $3.2(1.4-7.7)$ & $1.4(1.2-6.6)$ \\
\hline
\end{tabular}

Adjusted For: Age, educational status, parity, gravidity, and previous histo:; of placenta praevia, previous retained placenta, previous Caesarian sections and abortions. 
No significant difference was however between cases and controls for twin deliveries $(3.2 \%$ vs. $2.2 \%$; $\mathrm{P}=0.72$ ). There was no significant difference between cases and controls in the number of patients with previous history of uterine surgery $(\mathrm{P}=0.47)$ although there was a statistical difference in the history of previous abortion $(50 \%$ vs. $22.8 \% ; \mathrm{P}=0.001)$.

The results of multiple logistic regression analysis of factors that are independently associated with placenta praevia are shown in Table 2. After making necessary adjustment, the presence of placenta abnormality and a history of previous placenta praevia were no longer significant. Women with a history of retained placenta were seven times more likely to have placenta praevia and those with history of previous caesarean section were five times more likely while those with prior abortion were two to three times more at risk of placenta praevia than those in the control group. Furthermore, grandmultiparous patients had two-foldincreased risk and women over the age of 35 years were one and a half times more at risk.

\section{DISCUSSION}

It is interesting to note that our study showed that women with a history of previous retained placenta have a six fold increased risk of placenta praevia. This is a factor that has not been noted in the past. This association is not readily explained but perhaps factors, which predispose to adherent placentation also encourage a low implantation. It is possible that endometrial damage occur during manual removal of the placenta, which would then predispose to low implantation in subsequent pregnancies.

The relationship between placenta praevia and previous caesarean section has been most investigated. Bender(3), almost four decades ago, first observed an increased frequency of placenta praevia among women with a scarred uterus. In our study, women with a past history of caesarean section were five times at risk of placenta praevia. This is in agreement with the results of earlier investigators (2,4-7). In a meta-analysis, Ananth et. al.(7) analysed data from four studies encompassing 170,640 pregnant women and found a dose response pattern of risk of placenta praevia with increasing number of previous caesarean deliveries. The odds ratio ranged from $4.5(95 \%$ CI 3.6-5.5) for one to as high as $44.9(95 \% \mathrm{CI} 13.5-149.5)$ for four or more prior caesarean deliveries.

Attempts had been made to explain the increased risk of placenta pracvia in the presence of a previous caesarean section scar. Although damage to the endometrial and myometrial lining is thought to predispose to a low placental implantation, this damage does not significantly occur at caesarean delivery accomplished with a lower segment incision. Other more logical mechanisms have been suggested and includes placental attraction(8) and adherence to a caesarean section scar(9). Clark et. al. (10) believed that the presence of a scar may retard the physiologic development of the lower uterine segment and consequently prevent migration of the os from the placenta.

This study confirmed past reports of increased risk of placenta praevia in women with a history of previous spontaneous or induced abortion $(2,6,7,11)$. Ananth $e t$. al.(7) showed that a history of spontaneous abortion was associated with a $70 \%$ increase in the risk of subsequent development of placenta praevia. This was in consonance with the works of Zhang and Savitz(4) who reported a dose response pattern with the number of abortions.

The possible mechanism for this association is thought to be due to the traumatic effect of surgical evacuation of the retained product of conception on the endometrium. We have no information whether abortions reported by cases and controls were followed by curettage, but in Nigeria surgical evacuation is routinely performed in most miscarriages including induced abortions. The association of placenta praevia with uterine trauma was illustrated by Rose et. al.(6) who demonstrated a significantly increased risk in patients who had dilatation and curettage completely unrelated to pregnancy.

Our results also confirmed that there is an increase in the risk of placenta praevia for increasing parity. Although we found an association between maternal age and placenta praevia, it was weaker than is increasing parity. This is in agreement with the findings of some authors(12,13) but not others(14).

The concept of 'placental migration' is thought to predispose the multipara to placenta praevia. The mechanism of this movement is still unclear but it is suggested that the upward displacement of a low-lying placenta is a product of lower uterine segment development that normally occurs as gestation advances and not as a result of actual placental migration(15) This means that the cervix moves away from the placenta rather than the placenta moving away from the cervix(16).

In the nulliparous pregnancy, lower uterine segment lengthening can occur weeks prior to labour, whereas in the multiparous woman, lower segment development and cervical effacement may be delayed until well into the labour process(16). Hayashi(17) suggested that such physiologic differences might explain how multiparity confers an increased risk of praevia. The demonstration of 70 -fold difference in the praevia incidence between nulliparas and grandmultiparas illustrates this point(18). Previous pregnancies may predispose to low placentation by other mechanisms. Each pregnancy whether ending in early termination or term birth, may damage the endometrium underlying the implantation site. These regions become unsuitable for subsequent implantation, which then occurs the lower uterine segment(19). 
Age was shown to predispose to placenta praevia in this study. In a population based case-control study, Zhang et. al.(4) had demonstrated a highly significant dose-response response association between maternal age and placenta praevia. Physiologically, as women age, collagen progressively replaces normal muscle in the walls of myometrial arteries(20). The atrophic changes that occur in older women may also result in defective vascularisation of the decidua(21). Both under perfusion and undervascularisation have been postulated to play a role in the development of placenta praevia(21,22), as implantation tends to occur in well vascularised areas.

In conclusion, our results show that factors which predispose to placenta praevia in southern Nigeria, are similar to those identified in the developed world.

\section{REFERENCES}

1. Studying maternal mortality in developing countries: rates and causes. A guidebook. Geneva. 1985; F.H.E./87.7.

2. Parazzini, F., Dindelli, M., Luchini, L., et. al. Risk factors for placenta previa. Placenta. 1994; 15:321-326.

3. Bender, S. Placenta previa and previous lower segment caesarean section. Surg. Gynecol. Obstet. 1954; 98:625.

4. Zhang, J., Savitz, D.A. Maternal age and placenta previa: A population-based, case-control study. Amer. J. Obstet. Gynecol. 1993; 168:641-645.

5. Abu-Heija, A.T., El-Jallad, F. and Ziadeh, Saeed. Placenta previa: Effect of age, gravidity, parity and previous eaesarean section. Gynecol. and obstetric investigation. 1999; 47:6-8.

6. Rose, G.I. and Chapman M.G. Aetiological factors in placenta previa-a case control study. Brit. J. Obstet. Gynecol. 1986; 93:586-588.

7. Ananth, C.V., Smulian, J.C., Vintzileos, A.M. The association of placenta previa with history of caesarean delivery and abortion: A meta-analysis. Amer. J. Obstet. Gynecol. 1997; 177:1071-1077.

8. Taylor, E.S. Editorial comments. Obstet. Gynecol. Surv. 1983; 38:96.
9. Baron, S.L. Antepartum Haemorrhage in: Sir Turnbull A. and Chamberlain G. (Editor) Obstetrics. Edinburgh, Churchill Livingstone. 1989: 469-481.

10. Clark, S.L., Koonings, P.P., Phelan, J.P. Placenta previa/ accreta and prior caesarean section. Obstet. Gynecol. 1985; 66:89.

11. Hendricks, M.S., Chow, Y.H., Bhagarath, B. and Singh, $\mathrm{K}$. Previous caesarean section and abortion as risk factors for developing placenta previa. J. Obstet. Gynecol. Res. 1999; 25:137-142

12. Nelson, H.B., Huston, J.E. Placenta previa. A possible solution to the associated high fetal mortality rate. J. Reprod. Med. 1971;7:188.

13. Pedowitz, P. Placenta previa: An evaluation of expectant management and the factors responsible for fetal wastage. Amer, J. Obstet. Gynecol. 1965;93:16.

14. Williams, M.A. and Mittendorf, R. Increasing maternal age as a determinant of placenta previa. J. Reprod. Med. 1993; 38:425-428.

15. Morrison, J. The development of the lower uterine segment. Obstet. Gynecol. 1979; 86:846.

16. Strong, TH Jr. and Brar HS. Placenta in twin gestations J. Reprod. Med. 1989; 34:415-416.

17. Hayashi, R.H. Abnormalities of placental implantation. In The human placenta: Clinical perspectives. Ed JP Lavery. Rockville, MD, Aspen Publishers, 1987; pp.115-129.

18. Green, J.R. Placenta abnormalities: Placenta previa and abruptio placentae. In Maternal-Fetal Medicine: Principles and practice. Ed RK Creasy, R Resnik. Philadelphia, WB Saunders. 1984; pp. 539-555.

19. Green, J.R. Placenta previa and abruptio placenta. In: Creasy, R.K., Resnik R., Eds. Maternal-Fetal medicine: principles and practice. Philadelphia: WB Saunders, 1989; pp.592-600.

20. Naeye, R.L. Maternal age, obstetrics complications and the outcome of pregnancy. Obstet. Gynecol. 1983; 61:210-216.

21. Cunningham, F.G., Mac Donald, P.C., Gant, N.F. Williams's obstetrics, ed. 18. Norwalk, Appleton \& Lange, 1989; pp. $712-716$.

22. Naeye, R.L. The duration of maternal cigarette smoking, fetal and placental disorder. Early Hum. Dev. 1979; 3:229. 237. 